\title{
An Evaluation of the Cultural Aspects in the University English Textbook, Well Read 1
}

\author{
Bakr Bagash Mansour Al-Sofi \\ Department of English, College of Sciences and Arts, University of Bisha, Saudi Arabia
}

\begin{abstract}
This descriptive study, first, seeks to identify the extent to which the different cultures (source culture, target culture, and international target culture) are represented in the textbook, Well Read 1 . This textbook is written by Laurie Blass, Mindy Pasternak, and Elisaveta Wrangell and published by Oxford University Press (2007). Second, it aims to recognize the way these cultural aspects are presented. Third, it ascertains the most dominant and portrayed culture(s) in the prescribed textbook. The content analysis method was employed to meet the abovementioned objectives, and Cortazzi and Jin's (1999) model was followed. The purposive sampling was applied to elicit the data from this textbook through selecting representative texts and passages. The findings clarified that the three cultures (source culture, target culture, and international target culture) are generally represented to varying degrees throughout this culturally-based textbook. Besides, the cultural aspects were explicitly and implicitly embedded in different cultural areas in the form of online, magazine, academic and timeline articles. Moreover, it is evident that the target and the international target cultures predominate with little reference to the learners' source culture, i.e. Islamic and Arabic culture (Turkey, Mediterranean, and Morocco). Being aware of the different cultural aspects and the inseparability of language and culture is crucial for an efficient use of English in diverse contexts.
\end{abstract}

Index Terms - cultural aspects, textbook evaluation, language and culture, content analysis, EFL learning, Saudi Arabia

\section{INTRODUCTION}

Language is culturally loaded in which one is unable to think of it without its culture. It indicates that learning a language goes beyond its boundaries; it is culture-bound. The textbook is a primary teaching aid and supporter for language teaching/learning in an academic context. It is a significant source of linguistic knowledge and many loaded cultural aspects. Ahmad and Shah (2014) confirmed that learners "feel influenced by the textbooks they exercise for learning English language and in the process they come across social, religious, cultural, and linguistic diversities" (p. 12). It is also known that culture is not about something consisting of facts to be learned or memorized, but it is about styles and behaviors that can be practiced and appreciated.

Regarding the context of this study, Alshammari (2015) pointed out that the in-use materials and methods of English language teaching in Saudi Arabia reflect Anglo-American cultural and linguistic norms and values, and therefore lack the diverse nature of English today and conflict with the Islamic discourses and values. He discussed the inadequacy of the English materials used in Saudi schools and universities and argued that English an International Language (EIL) framework should be implemented in English curricula at all levels. This study accounts for the analysis and evaluation of the representation of the different cultures, the inclusion of cultural aspects, and the dominant culture(s) in the textbook, Well Read 1. It takes into consideration Cortazzi and Jin's (1999) model of the classification of cultures (source culture, target culture, and international target culture).

\section{REVIEW OF THE LITERATURE}

Textbooks play a pivotal role in the realm of language teaching/learning. They are a source of not only linguistic knowledge but of different cultural aspects as well. As noted by Cotazzi and Jin (1999), textbooks serve many roles in an EFL classroom, namely teacher, map, resource, trainer, authority, and ideology. They can be a map in the sense that it gives an overview of a structured program of linguistic and cultural elements, showing teachers and learners the grounds to be covered and summarizing the route taken in previous lessons.

\section{A. The Inseparability of Language and Culture}

Nowadays, culture has become a much-discussed topic in the field of English language and interculturality. McDaniel and Samovar (2014) stated that culture "is an extremely popular and increasingly overused term in contemporary society" (p. 9). Language and culture has received a considerable attention as they are strongly interrelated (Al-Hajailan, 1999; Brown, 1994, 2000; Byram, 1989; Fageeh, 2011; Han \& Bae, 2005; Ho, 2009; Jamalvandi, 2013; Jiang, 2000; Kramsch, 1993; Mitchell \& Myles, 2004; Peterson \& Coltrane, 2003; Scarcella \& Oxford, 1992; Seelye, 1976; Singhal, 1998). Seelye (1976) regarded that knowledge of linguistic structure alone does not carry with it any special insight into the political, social, religious, or economic system. According to Brown (2000), 
"A language is a part of a culture, and a culture is a part of a language; the two are intricately interwoven so that one cannot separate the two without losing the significance of either language or culture" (p. 177). Likewise, Byram (1988) asserted that language always refers to something beyond itself: the cultural context. These eminent scholars believe in the strong and dynamic relationship between language and culture in which they are bound together and cannot be separated. It signifies that being aware of the target language culture is not an option, but a crucial necessity for learning that language. Otherwise, the learner will be considered as a "fluent fool" "who speaks a foreign language well but does not understand the social or philosophical content of that language" (Bennett, 1993, p. 9).

Another renewed interest of the closely related terms of language and culture has led to their combination as one such as linguaculture (Fantini, 1997; Friedrich, 1989; Kramsch, 1993), languaculture (Agar, 1994; Risager, 2005) languageand-culture (Byram, 1997; Liddicoat, Papademetre, Scarino, \& Kohler, 2003) or culturelanguage (Papademetre \& Scarino, 2006). These intermingled terms have a common ground and are tied together. They should be looked at and acquired jointly to ensure efficient use of the language.

\section{B. Culture: The Fifth Language Skill}

Based on its importance and in addition to the receptive and productive skills, culture is fast becoming an essential element in language teaching and learning. It is an object of research as a fifth language skill (Hong, 2008; Jourdini, 2007; Kramsch, 1993; Tomalin, 2008; Vernier, Barbuzza, Giusti, \& Moral, 2008). Kramsch (1993) considered culture an "expandable" fifth skill tacked on to the teaching of speaking, listening, reading and writing. If language is regarded as a social practice, then culture should become the core of language teaching to the extent that cultural awareness should be viewed as enabling language proficiency. In the same vein, Vernier et al. (2008) viewed the teaching of culture as a fifth skill for language learners that "enhances students" overall learning experience" (p. 268). More important, Kramsch (1993) argued that the role of culture in language teaching is even more central, calling it not just a fifth skill, but rather something that is "always in the background, right from day one" (p. 1). Valdes (1986) stated that teaching a foreign language without its cultural content is practically impossible. These researchers hold the view that culture is a crucial part of language learning, and that language learning goes beyond acquiring language skills. Based on this, it can be confirmed that learner's awareness of the importance of culture as a fifth skill enables him/her to recognize, appreciate and accept cultural differences, and hence communicate successfully in different contexts.

\section{The Representation of Different Cultural Aspects in the Textbooks}

McKay (2000, 2002) emphasized that language teaching materials should include a variety of cultural elements, including local cultural, to help learners develop an interest in language learning and to foster learner motivation and should not be limited to native English-speaking countries. Similarly, Han and Bae (2005) claimed that "it is impossible to teach the target language without teaching its cultural content" (p. 52). It is not a call to separate the teaching of culture from language, but rather to furnish students with cultural awareness and experiences.

In line with McKay (2000), Cortazzi and Jin (1999) and Cortazzi (2000) viewed culture learning through textbooks as a process of a three-party dialogue between teacher, students, and textbook contents. As it is shown in Figure 1, Cortazzi and Jin (1999) distinguish between three types of cultural aspects that should be presented in culturallyoriented textbooks:

- Source culture materials refer to the learners' native culture;

- Target culture materials relate to the culture of the country where the target language (English) is practiced as a first language, e.g., American or British culture;

- International target culture materials refer to various cultures where the target language (English) is used as a global language, namely lingua franca. They thought that the ideal is some combination of $\mathrm{C} 1, \mathrm{C} 2$, and $\mathrm{C} 3$. Therefore, this classification helps in analyzing the representation of cultural aspects in the textbook under investigation.

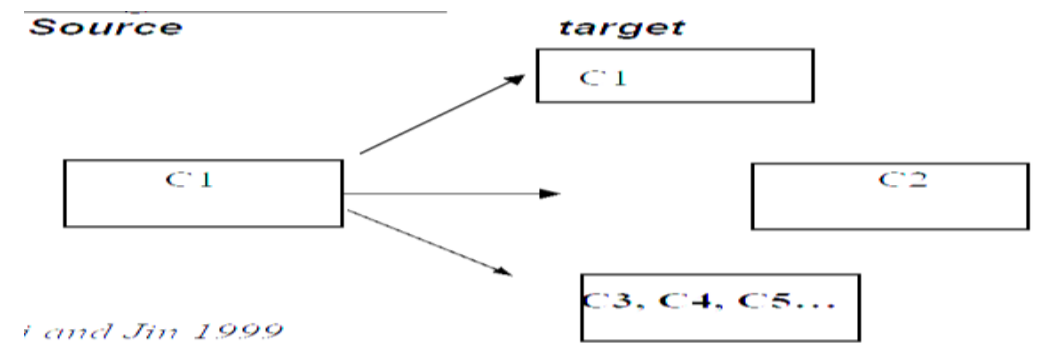

Figure 1: Representation of Culture in English Textbooks (adopted from Cortazzi \& Jin, 1999).

Keys: $\mathrm{C} 1=$ the learner's own culture (the source culture)

$\mathrm{C} 2=$ the target culture where the target language is used as a first language

$\mathrm{C} 3, \mathrm{C} 4, \mathrm{C} 5 \ldots=$ the cultures that are neither the source nor the target culture (international).

In the Saudi context, Fageeh (2011) conducted a study and highlighted that "integrating culture in the language classroom practices can be understood as important, apposite and necessary" (p. 67). Likewise, Alshammari (2015) explained that "Saudis need to learn to appreciate and understand the myriad values reflected in both native and non- 
native varieties of English, and also to express their own indigenous ideals through their English communications, rather than just 'foreign' ones" (p. 370).

What can be drawn from the literature reviewed so far supports the predominant view that learning a language has a vital cultural dimension, along with its linguistic one. The inclusion of such cultural aspects in the textbooks and referring to them while teaching the language help students to deepen their understanding, appreciate the cultural differences, and use the language efficiently. To put it simply, being aware of different cultural aspects is not challenging as long as we use the language successfully and maintain our identity and values. Likewise, understanding culture does not necessarily mean practicing it. Instead, as there are many universal cultural similarities, it can be said that there is common ground among cultures and what combines them is more than what makes them different.

This section refers to some of the previous studies dealt with the representation of culture in school and university textbooks in different contexts. Han and Bae (2005) used a cultural checklist to investigate the extent to which cultural content is integrated into Korean college English textbooks and whether there is a difference in cultural content written by native speaker writers and Korean ELT writers. The results indicated that it is difficult for textbook writers to include balanced information about the different cultural aspects in limited pages of textbooks. Moreover, there was not much difference in cultural content between materials written by native speaker writers and those written by Korean ELT writers. The study proposed that textbook writers should make more informed and appropriate cultural choices before designing the textbook.

Jamalvandi (2013) examined the representation of source, target and other cultures in the Chinese English school textbooks, New Senior English for China. He also investigated the way cultural elements are treated in the textbooks. The results revealed that the target culture $(\mathrm{C} 2)$ is represented more than source culture $(\mathrm{C} 1)$ and other cultures. Further, there was an imbalanced portrayal of the significant cultural aspects in which the most emphasis was given to the category of religion, arts, and humanities under which came subcategories including literature, arts, music, etc. Specifically, there were some areas of culture, like personal, which were underrepresented. Although some cultural dimensions emerged adequate, there was a biased representation of culture. Consequently, such textbook could not deepen and enrich students' cultural knowledge.

Chao (2011) studied cultural content and its hidden curriculum of the Taiwanese EFL textbook, New American Inside Out (elementary level/2008) by Macmillan. The results of the content analysis approach showed that this textbook promoted different cultural dimensions with a biased focus on the introduction of the elements of the target culture, with less portrayal of the source and international target cultures.

Bahrami (2015) evaluated teachers' perception of the cultural elements of Total English book series. A questionnaire was administered to a total of 50 male and female teachers working at Kish Language Institute in Esfahan. It was found that the textbook is biased in promoting the western culture and values much more than other cultures. Moreover, the cultural elements were mostly incompatible with the L1 (Iranian) culture.

Aliakbari (2004) employed the content analysis method to address the state of culture in the Iranian high school ELT textbooks. The results revealed that the representation of cultural elements is shallow and distract from culture or cultural points. The textbooks are therefore inadequate to the task of teaching culture specifics in the broader sense (values, norms, beliefs, etc.) or culture-general skills such as intercultural communication and understanding.

Taking into account Kachru's (1986) three-concentric-circles model, Elham and Reza (2013) examined the extent these textbooks portray the cultural themes of the three circles: New American Streamline (Hartley \& Viney, 1994), Cambridge English for Schools (Littlejohn \& Hicks, 1996), Interchange Series $3^{\text {rd }}$ Ed. (Richards, Hull, \& Proctor, 2005), and Top Notch (Saslow \& Ascher, 2006). Using the content analysis method, the results reported differences among the selected books with a gradual tendency towards more recognition of the international status of English. Moreover, these textbooks generally try to depict more aspects of the Expanding and Outer Circle countries.

Yasemin and Reyhan (2011) investigated the extent to which 18 locally published English textbooks contain cultural references to the source (Turkish) culture, the target (British/American) culture, and the international target culture. The quantitative analysis demonstrated that while references to the source and target cultures included in textbooks published between 1997 and 2005 outnumber international target cultural components, a different trend was obtained in the cultural analysis of books released after the 2005 curriculum innovation. The study stated that representations of the source culture, the target culture, and the international target culture are favored in locally produced ELT textbooks in a reasonably balanced way.

Cakir (2010) analyzed the frequency of culture-specific elements and expressions in English language course books used in the $6^{\text {th }}, 7^{\text {th }}$ and $8^{\text {th }}$ grades of Turkish elementary schools. The descriptive content analysis was employed and the results indicated that the textbooks are inadequate in supplying learners with culture-specific elements. Besides, the number and frequency of the cultural expressions is quite less and do not help learners to be exposed to the authentic and realistic situations in the target language.

Al-Akraa (2013) evaluated the content of the $5^{\text {th }}$ grade beginning English textbook, Iraq Opportunities 3, introduced in elementary schools based on grammar, vocabulary, and culture. Using the English teachers' questionnaire and the researcher's evaluation, it was clear that there were a limited role and a poor representation of culture in the investigated textbook. 
Bataineih (2009) carried out a study to find out the amount of authentic and artificial cultural aspects in the English language textbooks of the secondary schools in Jordan. After analyzing the content, it was observed that the textbooks are basically based on the learners' local culture, while the authentic target culture is ignored. It was also found that the sociocultural content is outdated which neither contributed to real understanding nor is it an adequate guide to successful communication in the foreign language being taught.

Sulaimani and Elyas (2015) investigated the representation of cultural aspects in the international teacher training course, Certificate in English Language Teaching to Adults (CELTA). They discussed the various aspects related to the importance of culture and its inclusion in the field of English Language Teaching (ELT). It was noted that teacher education program designers in general and CELTA course designers, in particular, must take account of the cultural and socio-political issues that are relevant to the contexts of the second language learners. Besides, incorporating cultural knowledge and socio-political issues into the CELTA syllabus not only would help language teachers acquire a basic starter pack of ELT methodologies, but it also would ensure that every aspect of the teacher's teaching practice is informed by a deep understanding of students' local intellectual conditions.

Mekheimer (2011) investigated the socio-cultural encounters of a case study, Saudi EFL learner in the College of Languages and Translation, King Khalid University. He used an in-depth interview to collect background data and a questionnaire to gather background information. The student's responses indicate a strong influence of the target culture on English learning. The student emphasized the significance of acculturation as part of second/foreign language acquisition/learning.

Alshammari (2015) discussed the inadequacy of the English materials used in the KSA schools and universities. He asserted that the Western cultural representations predominate in which the Saudi English courses are based almost entirely on US textbooks, taking no regard of the Arabic or Islamic culture, and contrast sharply with the traditions and values of the Saudi lifestyle. In a similar vein, Elyas (2011) analyzed the textbook used for $1^{\text {st }}$-year English students, Interactions 1 and found many standpoints that potentially conflict with primary Islamic discourses (especially those focused on home and family). It is recommended that the issues of sociocultural identity and representation need more attention through the implementation of an EIL framework in Saudi English curricula at all levels.

Ahmadi and Shah (2014) examined the impact of English textbooks (New Headway Plus Special Edition) on Saudi EFL learners' cultural attitudes and their English proficiency outcome. The findings of the questionnaire revealed that the textbooks writers adopted the mono-cultural and Eurocentric approach regarding the book's contents with slight cosmetic changes to make it 'Saudized'. They fail to foster the element of intercultural understanding mainly due to nonexistent Islamic or Saudi depiction; however, on the contrary, its impact on learners' performances was not much dispiriting. Moreover, a significant relationship between the English proficiency and the cultural attitudes of Saudi EFL learners was identified in which learners with excellent English proficiency achieved better mastery in not only the linguistic aspects of the language but absorbed its cultural elements as well in comparison to those who were less proficient.

Al-Hassan (1992) investigated the role and effects of culture and schemata on reading comprehension among King Suad University students. This thesis is concerned about cultural attitudes partly as those attitudes express themselves through reading. A questionnaire was used to determine the students' attitudes towards Western culture, and the extent of their impact on reading comprehension. The findings showed that Saudi students lack the cultural knowledge needed to understand British culture properly. Therefore, it was approved that 'cultural studies' be included in the foreign language syllabus. Understanding a foreign culture can lead to positive attitudes towards the language of that culture. Also, by teaching cultural studies, students' ethnocentricity is often reduced, and they become aware of the common bonds they have with others. They also learn to become more tolerant of existing differences between the target culture that will lead to cross-cultural awareness.

In view of the studies mentioned so far, it is evident that many of these studies dealt with the aim of analyzing and evaluating school textbooks at public education. Some studies concluded that most of the analyzed school textbooks generally do not meet the learners' needs and the teachers' expectations. They concentrate on the learners' source culture, neglecting the target culture and other international target cultures (Ahmadi \& Shah, 2014; Al-Hassan, 1992; Elyas, 2011; Fageeh, 2011). Other studies found that the target cultures are dominant with very less portrayal of the source culture.

Nevertheless, it is strongly confirmed that the inclusion of cultural content in language teaching materials is essential to help students interpret and understand the target culture, compare it with their native culture, and enhance their awareness of their own native culture (Alsamani, 2014). Supporting this idea, Fageeh (2011) confirmed:

language materials must incorporate at least the essential information about the cultural values and norms of the target culture in order to give learners the chance to understand not only the linguistic code of the English language, but also to be able to communicate effectively with its native-speaking community in ways that ease intra-cultural understanding, and inter-cultural communication without falling prey to cultural misunderstandings. (p. 67)

Moreover, he actively confirmed that the teacher "should never neglect the significance of culture in EFL teaching and should make effort to enhance students' cultural awareness" (p. 70). It does not mean calling for replacing teaching language with culture, nor does it call for teaching culture separately; instead and to be well-acquired, language can be 
taught with reference to its culture implicitly or explicitly through the inclusion of different topics and activities from different cultures.

\section{METHODOLOGY}

\section{A. Objectives and Design of the Study}

This study has three main objectives: to recognize the extent of the representation of the three cultures: source, target, and international target cultures in the English textbook, Well Read 1; to know the way the different cultural aspects are portrayed; to ascertain the dominant culture(s) in the prescribed textbook. The design of the study is descriptive bearing in mind Cortazzi and Jin's (1999) classification of cultures. It depends on the emic perspective through qualitatively analyzing the cultural aspects available in the target textbook.

\section{B. Statement of the Problem}

Studying and investigating cultural diversity is a hot spot and on the rise today. Specifically, each textbook varies in its content and approach to the various aspects of source culture, target culture, and the international target culture. Earlier, it is negatively assumed that linguistic knowledge is sufficient for successful use of the language, neglecting the importance of cultural knowledge. Moreover, some textbooks still focus on developing the receptive and productive skills only, and cultural aspects remained hidden from the learners and out of the teachers' intention. Particularly, the English language in Saudi Arabia is separated from its culture until recently (Elyas, 2011; Fageeh, 2011). Hence, this study seeks to remedy this issue by evaluating Well Read 1 textbook regarding its portrayal of the different cultures and the representation and forms of cultural aspects.

\section{Rationale behind the Study}

As the textbook is used on a large scale and is considered one of the vital channels for developing students' cultural knowledge, the supposed cultural aspects in the target textbook should be evaluated rather than taken for granted. In this regard, Ahmadi and Shah (2014) revealed that Saudi students "attain their first interaction with the target culture through these expressly adapted and customized textbooks" (p. 12). Moreover, believing in the fact that language is culturally-loaded, this textbook is evaluated against the representation of the different cultures and the inclusion of their aspects. To date, many of the prior studies have not explicitly achieved such objectives regarding this specific textbook using the content analysis approach. Moreover, the researcher has taught this textbook for four years so the question that immediately has come to mind is how the cultural representation and the supposed cultural aspects can help the students to be more knowledgeable and then competent communicators. Therefore and as learning a language goes beyond the knowledge of grammatical rules, this issue is worth considering bearing in mind the boost of the students' cultural awareness.

\section{Research Questions}

This study aims to address the following questions:

RQ1. To what extent do the different cultures are represented in the examined textbook?

RQ2. How are the various cultural aspects presented in the examined textbook?

RQ3. What is the most dominant culture(s) in the examined textbook, i.e. C1, C2, C3?

\section{E. Hypotheses}

It is strongly believed that learning/teaching any language without paying ample attention to its cultural aspects is insufficient and does not lead to efficient use of that language. To this end, it is hypothesized that the in-use textbook has some references, hints, and signals to the source, target, and international target cultures either explicitly or implicitly. It is also assumed that the various cultural aspects are presented in different forms. As the textbook is written by English native speakers, it is postulated that the target culture predominates with very less reference to the source culture.

\section{F. The Textbook under Investigation}

It is worth referring that the digital copy of the prescribed book is available at http://gen.lib.rus.ec/search.php?req=Well+read\%3A+skills+and+strategies+for+reading\&open=0\&res=25\&view=simpl e\&phrase=1\&column=def. The data of the study are drawn from the textbook: Well Read 1: Skills and Strategies for Reading. It was written by Laurie Blass, Mindy Pasternak, and Elisaveta Wrangell, and published by Oxford University Press (2007). It is thought that the intended audience of this textbook is the international students in which any reader feels as he/she is part of the audience. This textbook is one of a four-level series that is taught in four semesters in English department at some Saudi universities like King Khalid University and Bisha University. It is also a compulsory course in other departments in the two universities. This study mainly analyzes one textbook within this series, Well Read 1, that is taught to level-one students.

As the title implies, the textbook is mostly devoted to one language skill, i.e. reading skill, which is focused on throughout the whole textbook. Reading skills (previewing, scanning, skipping, and skimming) aim to prepare students to read well and quickly. Writing skill and the practice of online research are also dealt with towards the end of each 
chapter but with less attention. The specific objectives of each unit are clarified at the beginning of each chapter. Hence, this textbook is analyzed as a material object in which its content and structure are highlighted.

\section{G. Research Instruments}

Content analysis is a research instrument that is widely used to analyze the content of written texts regarding the inclusion of specific words and concepts and the relationship between them (Wallen \& Fraenkel, 2001). Consequently, the content analysis method is used to meet the abovementioned objectives by investigating the extent of the representation of the different cultures in the textbook, the forms of the various cultural aspects, and identifying the dominant culture(s). It is used to analyze the well-known cultural aspects of values, customs, traditions, music, sport, ethics, etc. This study employs the emic perspective through exploring textual culturally-bound data from within the assigned textbook. Moreover, essential and useful information can be drawn from the researcher's observation of a 4year teaching experience of this course as well as from the informal discussions with the teachers assigned to the evaluation committee of the curricula and study plans.

It could be assumed that this textbook achieves the quality and validity standards as it is published by the famous international publisher, Oxford University Press. Moreover, it is approved by the National Commission for Academic Accreditation and Assessment (NCAAA) in Saudi Arabia to represent 'Reading Comprehension 1' to level-one students in English Department and other departments as a compulsory course.

\section{H. Data Collection Procedure}

This study depends on the analysis of the taken-for-granted cultural ideas and concepts represented in the texts and pictures. Therefore, the linguistic features are analyzed regarding their representation of cultural aspects. Namely, the unit of analysis is the explicit words and the implicit units that embed culture and its related themes such as music, sports, foreign food, movies, ethics, fashion, etiquette, and generally any aspect of lifestyle. Based on the literature, these cultural aspects are considered as checklist and criteria for the evaluation process. The in-use textbook, Well Read 1 , is chosen for evaluation as the students have used it in the classroom on a large scale. Moreover, it is one of the critical channels for developing their cultural knowledge.

\section{Data Analysis Procedure}

For achieving the purpose of the study, the coding system is used in which the cultural ideas are categorized into words, phrases, clauses, sentence, themes, paragraphs, and whole text according to their mention in the chapters. With some hints to the frequency of the cultural aspects, the descriptive qualitative approach is employed in which the data are analyzed and discussed in the form of statements and sentences. Moreover, the textbook-evaluation process highlights the macro-features of the textbook regarding its design and layout, table of contents, and organization of units and sections. On the other hand, the frequently used model of culture proposed by Cortazzi and Jin (1999) and McKay (2000) (the Source culture, the Target culture, and the International Target culture) is taken into account. The different cultural aspects such as values, beliefs, customs, traditions, ways of dressing and eating, sports, the portrayal of other cultures, etc. are also investigated.

\section{DISCUSSION}

\section{A. The Layout of the Textbook}

The investigated textbook consists of eight chapters covering different topics and themes from a wide range of genres such as the magazine, newspaper, Internet, and academic articles. Besides, various graphics of tables, charts, timelines, and illustrations are used. On the left-hand page of each chapter, many aspects are mentioned such as reading skills, vocabulary strategy, and graphics. The authors used brainstorming activity in which the students are encouraged to recall their background knowledge through questions before, within, and after each text in the form of filling the blanks, ticking, multiple choice questions, direct questions with short answers, giving synonyms and antonyms, completing answers, true/false, matching, definitions, parts of speech, and identifying the topic, main idea, and supporting details. The choice of such tasks and activities can be justified as a way to enable students to think critically, draw connections across ideas, and apply their prior knowledge and experiences. In other words, various activities are designed in every chapter such as getting started, active previewing, reading and recalling, understanding the text, reading skills, vocabulary strategies, discussing the issues, putting it on paper, and taking it online. Each idea has its objective in helping the students to practice reading skills, get new vocabulary, discover other cultures, develop students' writing skill and practice online research to discuss different cultural issues. Concerning the design and structure, it can be stated that the chapters and sections, i.e. the headings/subheadings, graphic organization, tables, proposed objectives, etc. are well-developed and well-organized.

\section{B. Representation of the Different Cultures}

This section highlights the presence of the different cultures in light of Cortazzi and Jin's (1999) model (source culture, target culture, and international target culture).

\section{The Source Culture}


Nelson (1994) argued that it is essential to recognize and reflect learners' source culture in language teaching because when we eliminate learners' cultural background, we are denying and devaluing their L1 and culture, and hence their identities. Similarly, Byram and Morgan (1994) indicated that learners cannot simply shake off their own culture and step into another as their culture is a part of themselves and created them as social beings.

Within the texts and passages of the book, there are only three items that refer to the students' source culture i.e. Islamic culture (Turkey, Mediterranean, and Morocco) such as the way of 'greeting' and the 'personal distance' in the Turkish culture and Mediterranean, and the dish of 'vegetarian tagine' from the Moroccan culture. The examples from Turkish culture are about the polite behavior, the way of greeting, and personal distance. These social and business etiquettes can be applied not only in Turkey but also in many other cultures. Similarly, the Moroccan dish 'vegetarian tagine' is famous especially in the African and European countries. In comparison with the target and international target cultures, it is noticed that the learners' source culture was given an imbalanced consideration and was relatively minimized. Specifically, a direct reference to the learners' source culture, i.e. Saudi culture is not found. If the university or the Ministry of Education designs such textbook, it is expected that a variety of topics from the learners' source culture will be portrayed, as it is clear in the English for Saudi Arabia textbook that is taught in Saudi public education. To this end, the inclusion of the students' source culture provides not only content that students are already familiar with, but also a means to develop their cultural consciousness. Learners are supposed to match up their culture to the target ones.

When we consider the textbook as a product, we can say that the authors have their justification in which the book is adhered to fit the publication policy, satisfy the readers, and meet the assigned objectives. Textbook writers may also encounter difficulty in covering all the cultures and subcultures in one textbook as no any culture is homogenous. More important, students themselves could not absorb and be aware of all the world cultures. In line with Han and Bae's (2005) study, it is difficult for textbook writers to include balanced information about the different cultural aspects in limited pages of textbooks. The study proposed that textbook writers should make more appropriate and up-to-date cultural choices before the textbook is written.

In fact, exposing global cultural aspects is healthy in which they let the students think and reflect the taken-forgranted elements of their source culture. Another point is that as the world has become a small 'global village', it can be said that what combines cultures is more than what keeps them separate. To put it differently, the global standards and good manners, starting with behaving politely and not ending with respecting others' beliefs and values, are common in most cultures. However, the course instructor also has an influential role in referring to the students' source culture and comparing it with others with the purpose of appreciation and better understanding.

\section{The Target and the International Target Cultures}

Textbooks written by native writers are likely to embrace different aspects of different target cultures. The target culture comprises English-speaking countries (America, England, Scotland, Wales, Canada, Australia, New Zealand, Jamaica, Ghana, South Africa, etc.). On the other hand, the international target culture includes all the countries where English is used as a lingua franca. Saluveer (2004) argued that "the easiest way to design a cultural syllabus is to compile a list of topics that are thought to be important for or of interest to students" (p. 22). Undoubtedly, understanding and being knowledgeable of a culture encompasses all its aspects of values, traditions, customs, food, movies and the use of technology, music, sport, ways of dressing and eating, ethics, etc. In this sense, the different cultural aspects that are exposed in the textbook are intensely discussed.

The Sociology of Food

Food is one of the central social themes of culture in which almost every culture has its types of food and ways of eating. Food also expresses a sense of identity and a means of retaining it. Besides, some food types are culture-bound in which what is eatable in one culture may be uneatable or banned in another.

Chapter one 'The Sociology of Food' mentions many types and styles of traditional and western dishes from different cultures and subcultures such as Florida (USA), Massachusetts (USA), California (USA), France, Ukraine, Taiwan, Puerto Rico, and Morocco. In this aspect, the target, the international target, and the source cultures are represented to varying degrees. It exhibits examples about the customs and traditions of eating food at schools and what these meals include. It also refers to the items that are included in the restaurant menus. This chapter helps readers to be aware of these differences and also sensitize them to the school and restaurant healthy food. Specifically, the term 'food' was mentioned 65 times in this textbook. To put it differently, diversity in food, its types and tastes, and the way of eating and sitting to eat are culture-bound and passed down from generation to another. Therefore, understanding the culture of food (what, when, how, how much and with whom to eat) is helpful for effective communication either at home or abroad.

\section{Movies and Music}

Movies and music are other cultural art themes that should be given careful thought. Watching movies and listening to music are also culture-bound. In this section, chapter 2 'Technology in Movies' and chapter 4 'The Culture of Music' are discussed together as they are interrelated. Chapter 2 is about movies and the use of technology and special effects in making films. It differentiates between real movies and the movies with special effects. It mentions some of the wellknown movies such as King Kong (1933, 2005), Jurassic Park, Alien, The Wolf Man, Titanic, The Matrix, Mission to Mars, The Mummy Returns, The Wizard of $\mathrm{Oz}$, etc. 
In addition to their entertaining purpose, movies provide an invaluable source of authentic language. They expose audience (students) to real-life conversation and expressions used in 'real' situations outside the classroom. In this sense, students can go beyond the entertaining aim to develop their linguistic knowledge and have greater knowledge and awareness about other cultures. In the assigned textbook, the terms 'movie' and 'moviegoer' were mentioned 132 times.

Chapter 4 "The Culture of Music" includes different international kinds of music such as rock (the Beatles and the Rolling Stones), jazz and classical music, the local symphony orchestra, world music, hip-hop, rap, etc. It also refers to different kinds of musical instruments from different cultures such as guitar, violin, cellos, flutes, drums, and the giant earth harp. Supporting this, the terms 'music', 'musical', and 'musician' were mentioned 157 times in all chapters. These musical aspects are widely used and elicited from different cultures.

Sports Psychology

As people are active and sporty, there are many texts on weird and high-risk sports and adventures such as skydiving, mountain climbing, wrestling, paintball, etc. In this study, the terms 'sports' and 'sportsmen' were mentioned 122 times. They looked at the benefits of sports from a psychological perspective and claimed that sports that expose unusual behaviors qualify people to be adventurous, patient, confident, excited, calm in personality, and successful in life. "Risk takers are often more successful than non-risk-takers: Inventors, politicians, and CEOs_-people who lead companiesare often risk-takers" (Blass et al., 2007, p. 48).

Global Community

Chapter 5 'Global Community' represents an environmental theme. It instills common good behaviors in the students' minds from the early childhood so as to sacrifice and work voluntarily in the team spirit for the benefit of themselves and the society as a whole. It reinforces some good traits like how to save the environment, be a genius and productive member in the community, and help others who are in crucial need. These are universal traits that all agreed upon in all cultures.

Another text 'A New College Course: What Motivates Altruism?' introduces good ethics and ways of behaving with others through cooperating and helping the poor, the needy and the homeless. It reflects that altruism is a typical value that is praised and approved by all communities. Giving an example from the target culture, professors and students from Chico State University (California) organized a college class at the university about altruism and the motivation behind it. They follow the targets, read books, and write papers. One student claimed, "I also learned that I can help others as a career".

Moreover, there is a fascinating image of patriotism and loyalty that is reflected by the student who said "I work for the community because the community helped me in the past" (Blass et al., 2007, p. 89). Another student said, "recognition for my work is not important" (p. 89). These attention-grabbing expressions sincerely reflect a true love for their society. It also cultivates altruism through helping others voluntarily without waiting for rewards or appreciation. People who sacrifice for helping others are "ordinary people doing special things". In this sense, the altruists convey a message to stimulate the students that altruism is not confined to a specific group of people, but rather anyone can practice it. Moreover, they encourage them to resemble great critical thinkers and philosophers such as Martin Luther King, Jr. and Emmanuel Kant (German philosopher) who knew the meaning of life and write about it. The authors also glorify the most influential people of the $20^{\text {th }}$ century. They divided them into four groups: leaders and revolutionaries (e.g. Winston Churchill), builders and titans (e.g. Henry Ford), scientists and thinkers (e.g. Albert Einstein), and heroes and icons (e.g. Mother Teresa). Based on their symbolic value, these influential characters represent successful stories from the global community which is an evidence of multiculturalism. They are named and referred to as geniuses, and many approved good traits and values are attributed to them.

Business Etiquette

Etiquette is one of the important social themes, and each culture has its unique etiquette in business situations. This chapter exemplifies a set of accepted behaviors in business situations from the international target and source cultures (Australia, Brazil, South Korea, and Turkey) such as polite business behaviors, introducing people to each other, ways of greeting, using cell phones, eating dinner or lunch in a restaurant, gifts giving, exchanging business cards, using the names and titles, etc. Moreover, the authors refer to the cultural differences in making eye contact and maintaining personal distance.

Another text is about 'Job Interviewing across Cultures'. It sensitizes students to the generally-accepted worldviews that should be followed in job interviews such as dressing, the role of the interviewee, correct etiquette, the pace of the interview, relationships, and the value of educational credentials and experience. The value and importance of such rules differ from culture to another. It should be borne in mind that there are different ways of doing things and one's way is not the only good one. Therefore, being aware of such actions and etiquette is crucial for achieving business goals especially when applying for job vacancies.

Fashion Philosophy

The fashion industry is an integral part of the culture, and the two go together. Fashion influences individual lifestyles, and this can be seen clearly in the way people dress and follow the latest fashion trends. Fashion and dressing, in general, are a way of attracting and identifying people and their cultures as they express cultural identity. It also goes beyond dressing to the way we communicate, decorate our homes and offices, buy cars and mobiles, choose meals, sit, eat, and even spend holidays. 


\section{Ethics in Education}

Ethics and morals are highly recommended and appreciated in all cultures. They should be applied in all aspects of our life. Specifically, this chapter provides significant lessons for the students to be aware of and promote their ethical thinking, especially in education. It deals with crucial ideas such as cheating, plagiarism, and cheating with technology. It also refers to the way of avoiding such illegal practices, i.e. citing sources. Cheating can happen not only at schools but beyond them as well. These malpractices are considered an unethical issue in education. They are cross-cultural and expected in different cultures. Hence, the ethical principles must be taught at schools and universities. As teachers are right ideals for their students, they have a moral obligation in encouraging the students to behave ethically, be aware that such misbehaviors are harmful, and that they have to be honest and follow the rules and the right ways.

Regarding 'cheating with technology', most of the educational institutions and businesses worldwide suffer from such malpractices. A possible explanation for this might be that technology is a two-edged weapon. Positively speaking, the technological revolution has democratized information and made it easy by one click to Google any topic or idea. AlSofi (2016) clarified that it "depends on the learners' motivation and their willingness to look at the shining educational side of these online means" (p. 94). It is apparent that high-tech devices (e.g., smart lenses, smart glasses, smart watches, and smart rings) are spread ubiquitously, and so much information can be stored on such devices.

On the contrary, these devices have transformed cheating to advanced ways and made it easier than before. Stopping such behaviors requires a joint responsibility to reach practical solutions. If used negatively, technology can create a 'copy and paste' generation. It also provides them with innovative tools for cheating either during study or exam.

This chapter directs students to the legal ways of searching and then acknowledging others' ideas through citing sources. These moral lessons have an essential effect on the students' minds. Hence, there should be an inner- and selfsupervision in every step towards learning and search for the truth and facts. Students should be straightforward and stay away from such wrong behaviors. Policymakers, on the other hand, should come up with innovative strategies and effective plans to stop such practices. One of these procedures is the use of software that can detect plagiarism. Students can also be punished and dismissed from either the program or the institution at all.

Concerning the use of some political themes, the 'French revolution' and the word 'revolutionaries' were mentioned clearly in this textbook and they were taught openly to the students. Such themes could lead to the fact that students should be aware of the history of other countries as the world is continuously becoming more globalized. The inclusion of foreign names and famous people (filmmakers, special effects genius, critical thinkers and philosophers) is also another example that has a symbolic value and reflects the diversity of cultures.

To sum up, this culturally-oriented textbook is globally designed as it represents aspects from the international target, the target, and source cultures (North and South America, Australia, France, Japan, Brazil, Ukraine, China, South Korea, Taiwan, Turkey, Morocco, Mediterranean) to varying degrees. It is clear that the texts and passaged are presented in a logical sequence starting with the food culture and ending with ethics in education. In accordance with Bahrami's (2015) and Chao's (2011) studies, the investigated textbook maximized the exposition of the diverse cultural elements from the target and international target cultures (food, music, ethics, sport, ethical values, fashion, etc.), and minimized the portrayal of the elements of the source culture. Hence it can be said that the dominant culture is the target and international target cultures despite the textbook writers are English native speakers.

Regarding the form of the different cultural aspects, the explicit and implicit representation of these aspects is manifested in the form of various genres such as online, magazine, academic and timeline articles. Hence, students can critically analyze these texts as part of literacy and, at the same time, experience the world and its cultures through such texts that are collected from different genres. In other words, the exposure of such cultural elements enables the students to be aware of not only linguistic knowledge but also of cultural knowledge that leads to language proficiency. Hence, it can be said that many of these cultural aspects can be recontextualized as we live in a 'global village' that shares most of the traits and qualities.

\section{FINDINGS}

Blass et al. (2007) asserted that the book includes "a wide range of authentic texts that are meant to engage students' (and teachers') interest" (p. iii). Taken together, the overall organization of the textbook and the themes included were satisfactory. The findings supported the assumption that the book under evaluation represents a wide range of cultural aspects from the target and international target cultures. Supporting Jamalvandi's (2013) study, the chosen textbook represented target culture (C2) more than source culture (C1) and other cultures. Additionally, the authors employed real situations for the reader (students) to be engaged in cultural themes and be put in a position to not only develop their reading skills (the main objective of the book) but to be critical and get knowledge about various cultural aspects as well.

Generally, it can be inferred that the authors have filled the gap and bridged the unrealized connection between learning/teaching language and culture. Undoubtedly, many of the texts include ethical values and behaviors that build the personality of the readers and are recommended and appreciated by many cultures. In other words, exposing students to authentic cultural materials and aspects (eating balanced meals, sports and good health, helping others, altruism, saving the environment, behaving well, avoiding cheating in all aspects of life, etc.) familiarize them with 
appreciating the importance of culture for successful interaction in real-life situations. They are spread across the whole book in which each chapter covered a variety of cultural aspects (see Tables $1 \& 2$ ).

As already mentioned, this textbook is culturally-based due to several viewpoints. First, though the focus is on the target and international target cultures, the prescribed textbook is generally based on the multicultural approach in the sense that it embodies a wide variety of materials and features from different international target culture, target culture, and source culture. More particularly, it refers to aspects of native and international cultures (North and South America, France, Australia, Japan, Brazil, Ukraine, China, South Korea, Taiwan, etc.) and from the learners' home culture (Morocco, Turkey, Mediterranean), but with less consideration. Such conclusion confirms Pennycook's (1994) idea that the internationally published textbooks are never neutral and they mainly represent the western understandings of language, communication, and learning. In Saudi context, English for Saudi Arabia textbook used in middle and secondary schools appeared to be an EIL textbook on the surface. However, Saudi nationalism and Islamisation are "heavily endorsed in the book, making it incompatible with today's motives to utilise English for international communication" (Alshammari, 2015, p. 369). Based on this, textbook writers can localize certain cultural aspects by adopting the target language culture without neglecting local cultural values. To complement each other, therefore, there should be a match between the secondary (public) and higher education textbooks.

TABLE 1:

SUMMARY OF THE FREQUENCY OF THE CULTURAL ASPECTS MENTIONED IN THE SELECTED BOOK

\begin{tabular}{|l|l|}
\hline Cultural words/terms & Frequency of reference \\
\hline Culture & 101 \\
\hline Music/musical/musician & 157 \\
\hline Movie/moviegoer & 132 \\
\hline Food & 65 \\
\hline Revolution & 4 \\
\hline Sport & 122 \\
\hline Ethics & 11 \\
\hline The total number of cultural items & 592 \\
\hline
\end{tabular}

TABLE 2:

AREAS OF THE INCLUDED CULTURAL ELEMENTS IN THE SELECTED TEXTBOOK

\begin{tabular}{|l|l|}
\hline Areas of Cultural Elements & Cultural Elements \\
\hline The Sociology of Food & School Lunches: main food, meals \\
& Restaurants Fare \\
& Food Inventions \\
& The History of the Restaurant \\
\hline Technology in Movies & A Movie Classic: movies \\
& A Special Effects Genius \\
& Special Effects Statistics \\
& Secrets from FX Experts \\
\hline Sports Psychology & Weird Sports \\
& Skydiving \\
& Sports Injuries \\
& Taking Risks in Sports: favorite sports \\
\hline The Culture of Music & Favorite Music \\
& Earth Harp \\
& Hit Songs \\
& Hip-Hop Music \\
\hline Global Community & A Young Environmentalist \\
& "Genius" Grants \\
& Making a Difference \\
& What Motivates Altruism? \\
\hline Business Etiquette & Etiquette Intelligence \\
& Polite Business Behavior: greeting, introducing oneself, giving presents \\
& Too Close or Too Far? \\
& Interviewing for a Job: getting jobs \\
\hline Fashion Philosophy & A Thai Fashion Designer \\
& The 80s Look \\
& Clothing Costs \\
& What Is Fashion? \\
\hline Ethics in Education & What Is Cheating? \\
& Plagiarism \\
& Citing Sources \\
& Cheating with Technology \\
\hline & \\
\hline
\end{tabular}

The results of this study are somehow inconsistent with the results of the previous studies due to many reasons. First, many of the prior accounts examined EFL textbooks assigned for public education at schools while this study analyzed a university textbook. Second, most of the school textbooks are 'localized' by non-native speakers of English and approved by Ministry of Education without balanced representation of the source, target, and international target cultures. In other words, locally designed EFL textbooks are mostly loaded with the learners' source culture (Cortazzi \& 
Jin, 1999). Third, some of the abovementioned studies were conducted in different contexts, other than the Saudi context.

Consequently, the imported textbooks written by native speakers are supposed to be culturally designed and balanced in representing different cultures. As English is used as an international language that is not confined to a particular country, Yasemin and Reyhan (2011) clarified that "a reasonably good balance between local, target and international target cultural elements in teaching materials is needed" (p. 157).

Based on the above-mentioned cultural aspects and themes, it can be said that intertextuality is deeply-rooted in the examined book as the texts and passages are interlinked and generally represent different cultural aspects. Specifically, the textbook under investigation does not impose specific cultural information on learners. Instead, learners are exposed to several adequate references such as food, sports, movies, music, ethics, etc. from a variety of cultures and cultural groups (French, China, Japan, Korea, Britain, USA, Turkey, Morocco, etc.). It is believed that these various types of cultural aspects and elements are directed towards international students especially that this textbook is printed by Oxford University Press, which mostly published globally-designed materials. Whatever the cultures incorporated in the prescribed textbook and in addition to the linguistic knowledge, the main aim is to enrich learners' awareness of the cultural differences that lead them to successful use of the language in different settings.

\section{CONCLUSIONS}

As cited earlier, this study aimed to achieve the following objectives: to recognize the extent of the representation of the three cultures: source, target, and international target cultures in the English textbook, Well Read 1; to know the way the different cultural aspects are presented, and to ascertain the dominant culture(s) in the prescribed textbook.

For answering the first research question: To what extent do the different cultures are represented in the examined textbook?, it could be affirmed that there is a tendency towards multiculturalism in which there is an adequate coverage of real references, examples, and indications to cultural aspects from a variety of cultures and countries rather than from specific native cultures (American or British). More specifically, it is clear that the texts and passages in the examined textbook expose students to a range of cultural aspects of the target language. These elements were penetrated throughout the whole book in areas such as food, movies, sports, music, etiquette, fashion, business, ethics, etc. Generally speaking, these references and hints symbolize and acknowledge interculturality (North and South of America, France, Australia, Japan, Brazil, South Korea, Ukraine, China, Taiwan, Turkey, Morocco, Mediterranean) of the textbook in question. However, this study sheds light on the limited presence of the cultural elements of the students' first culture or the expanding cultures in general. It is noteworthy that textbooks are not the sole source of culture. Rather, cultural awareness could be upgraded through the Internet, the media, or even through human interaction especially in this global era. In this regard, Al-Sofi (2016) clarified that language and culture could "be acquired from other sources beyond the classroom boundaries; online communication tools are but one of them" (p. 99). This textbook tried to link language learning with cultural activities and behaviors outside the classroom.

Concerning the answer to the second question: How are the various cultural aspects presented in the examined textbook?, one could note that these cultural aspects are explicitly and implicitly exposed. The explicit elements are easily recognized through the cultural areas of food, movies, sports, music, etiquette, fashion, business, ethics, etc. Others are implicitly embodied through the recognition and analysis of the attached photos, pictures, and illustrations. Moreover, most of the texts can be classified as online, magazine, academic and timeline articles. These texts and passages are useful in showing the different aspects of cultures irrespective of race, ethnicity, religion, culture, and language. In other words, the voice of the authors is clear in trying to convince the audience to believe in cultural diversity. Rather than confining the students to one source, exposing them to different texts and passages from different sources is a healthy phenomenon.

Regarding the answer to the third research question: What is the most dominant culture $(s)$ in the examined textbook, i.e. $C 1, C 2, C 3$ ?, the investigated textbook maximized the exposition of the diverse cultural elements from the target and international target cultures and minimized the portrayal of the elements of the source culture. Hence, it can be said that the dominant culture is the target and international target cultures.

This study makes an original contribution to the existing accounts as cultural awareness is better acknowledged and highly recommended for raising cultural awareness for the time being. Specifically, it highlights the close relationship between language and culture and the crucial role of exposing learners to the different cultural aspects. It also sheds light on such evaluation and analysis for directing future researchers to such studies. It might provide food for thought for policymakers, curriculum planners, syllabus designers, teachers, and students to share the responsibility and reconsider the teaching/learning of culture, alongside language.

\section{A. Limitations of the Study}

As mentioned earlier, this study has a scope of one textbook from the Well Read series. It is noteworthy that the intent is not to generalize the findings as other Saudi universities assign other series for reading courses such as Interactions (Reading) (Middle East Gold Edition) by Hartmann and Kirn (2009), and New Headway Plus by John Soars and Liz Soars (2013). Taking account of the analysis of one textbook from this series could be considered a 
limitation. Hence, future studies can broaden the analysis of such cultural aspects to include representative texts from the other books of Well Read series.

\section{B. Recommendations of the Study}

Based on the findings and supporting Ahmadi and Shah's (2014), Al-Hassan's (1992), Alshammari's (2015), and Fageeh's (2011) recommendations, such results should be translated into actions in the sense that English textbooks should be based on a balanced portrayal of different cultural aspects. Additionally and as cultures are dynamic, this textbook can also be updated regularly according to the international changes and students' needs. To keep students upto-date, teachers can even play a pivotal role to integrate culture, as a fifth language skill, into the classroom and highlight its equal importance to other skills. On the part of the students, they can exploit every touch logging in the social networks and mass media for keeping in touch and raising their cultural awareness.

\section{REFERENCES}

[1] Agar, M. H. (1994). Language shock: Understanding the culture of conversation. New York: William Morrow.

[2] Ahmadi, H., \& Shah, S. R. (2014). EFL textbooks: Exploring the suitability of textbook contents from EFL teachers' perspective. VFAST Transactions on Education and Social Sciences, 5(1), 12-20.

[3] Al-Akraa, S. (2013). Teaching English in Iraq: An analysis of an EFL textbook. MA thesis, the University of Central Florida Orlando, Florida.

[4] Al-Hajailan, T. A. R. (1999). Evaluation of English as a foreign language textbook for third grade secondary boys' schools in Saudi Arabia. Doctoral dissertation, Mississippi State University. Department of Curriculum and Instruction.

[5] Al-Hassan, A. M. S. (1992). The effects of culture and schemata on reading comprehension of university readers. PhD dissertation, University of Surrey.

[6] Aliakbari, M. (2004). The place of culture in the Iranian ELT textbooks in high school level. Paper presented at The 9th Panpacific Association of Applied Linguistics Conference, Namseoul University, Korea.

[7] Alsamani, A. S. (2014). Foreign culture awareness needs of Saudi English language majors at Buraydah Community College. English Language Teaching, 7(6), 143-153.

[8] Alshammari, A. K. (2015). Developing the English curriculum in the Kingdom of Saudi Arabia: Possibilities and challenges. Arab World English Journal (AWEJ), 6(4), $365-372$

[9] Al-Sofi, B. B. M. (2016). The impact of online communication on learning English: A case study of Saudi EFL learners. International Journal of Applied Linguistics and English Literature (IJALEL), 5(4), 91-101, doi:10.7575/aiac.ijalel.v.5n.4p.91.

[10] Bahrami, N. (2015). Evaluating the representation of cultural elements in an in-use EFL textbook. Advances in Language and Literary Studies, 6(3), 128-137.

[11] Bataineih, A. (2009). An evaluation of the authentic sociocultural elements in the prescribed English language textbooks of the secondary schools in Jordan. An-Najah Univ. J. Res (Humanities), 23(1), 290-324

[12] Bennett, M. J. (1993). How not to be a fluent fool: Understanding the cultural dimension of language. The language teacher, 27(9), 16-21.

[13] Blass, L., Pasternak, M., \& Wrangell, E. (2007). Well Read 1: Skills and strategies for reading. Oxford: Oxford University Press.

[14] Brown, H. D. (1994). Principles of language learning and teaching ( ${ }^{\text {rd }}$ ed.). Englewood Cliffs, NJ: Prentice Hall Regents.

[15] Brown, H. D. (2000). Principles of language learning and teaching ( $4^{\text {th }}$ ed.). New York: Longman.

[16] Byram, M. (1988). Foreign language education and cultural studies. Language, Culture, and Curriculum, 1(1), 15-31.

[17] Byram, M. (1989). Cultural studies in foreign language education. Clevedon, UK: Multilingual Matters.

[18] Byram, M. (1997). Teaching and assessing intercultural communicative competence. Clevedon: Multilingual Matters.

[19] Byram, M., \& Morgan, C. (1994). Teaching and learning language and culture. Great Britain: WBC. Fransisco: Jossey-Bass Publications.

[20] Cakir, I. (2010). The frequency of specific culture elements in ELT textbooks at elementary schools in Turkey. Novitas-ROYAL (Research on Youth and Language), 4(2), 182-189.

[21] Chao, T. (2011). The hidden curriculum of cultural content in internationally published ELT textbooks: A closer look at New American Inside Out. The Journal of ASIA TEFL, 8(2), 189-210.

[22] Cortazzi, M. (2000). Languages, cultures, and cultures of learning in the global classroom. In H. W. Kam, \& C. Ward (Eds.) Language in the global context: Implications for the language classroom (pp. 75-103). Singapore: SEAMEO Regional Language Centre.

[23] Cortazzi, M., \& Jin, L. (1999). Cultural mirrors, materials and methods in the EFL classroom. In E. Hinkel (Ed.), Culture in second language teaching and learning (pp. 196-219). Cambridge: Cambridge University Press.

[24] Elham, N. M., \& Reza, P. (2013). Analysis of English language textbooks in the light of English as an International Language (EIL): A comparative study. International Journal of Research Studies in Language Learning, 2(2), 83-96.

[25] Elyas, T. (2011). Diverging identities: A 'contextualised' exploration of the interplay of competing discourses in two Saudi university classrooms (Doctoral dissertation). University of Adelaide: Australia.

[26] Fageeh, A. (2011). At crossroads of EFL learning and culture: How to enhance cross-cultural awareness in EFL college students. Cross-cultural Communication, 7(1), 62-72.

[27] Fantini, A. (1997). Language: Its cultural and intercultural dimensions. In A. Fantini (Ed.). New ways of teaching culture (pp. 3-15).Alexandria, VA: TESOL Publications.

[28] Friedrich, P. (1989). Language, ideology and political economy. American Anthropologist, 91, 295-305.

[29] Han, Y., \& Bae, Y. (2005). An analysis of the cultural content of high school and college English textbooks. English Teaching, 60(4), 47-70. 
[30] Ho, S. T. K. (2009). Addressing culture in EFL classrooms: The challenge of shifting from a traditional to an intercultural stance. Electronic Journal of Foreign Language Teaching, 6(1), 63-76.

[31] Hong, S. (2008). The role of heritage students in incorporating culture into language teaching. South Asia Language Pedagogy and Technology, 1, 1-10.

[32] Jamalvandi, B. (2013). Realization of culture in English textbooks in Chinese high school level. Journal of Pan-Pacific Association of Applied Linguistics, 16(2), 89-101.

[33] Jiang, W. (2000). The relationship between culture and language. ELT Journal, 45(4), 328-332.

[34] Jourdini, M. (2007). The fifth skill: Culture as a language learning motivator. http://www.stoa.org. (accessed 06/05/2017).

[35] Kramsch, C. (1993). Context and culture in language teaching. Oxford: Oxford University Press.

[36] Liddicoat, A. J., Papademetre, L., Scarino, A., \& Kohler, M. (2003). Report on intercultural language learning. Canberra ACT: Commonwealth of Australia.

[37] McDaniel, E. R., \& Samovar, L. A. (2014). Understanding and applying intercultural communication in the global community: The fundamentals. In L. A. Samovar, R. E. Porter, E. R. McDaniel \& C. S. Roy (2014). Intercultural communication: A reader (14 ${ }^{\text {th }}$ ed.) (pp. 5-15). Cengage Learning: USA.

[38] McKay, S. L. (2000). Teaching English as an international language: Implications for cultural materials in the classroom. TESOL Journal, 9(4), 7-11.

[39] McKay, S. L. (2002). Teaching English as an international language. Oxford: Oxford University Press.

[40] Mekheimer, M. A. (2011). Impact of the target culture on foreign language learning: A case study. Cross-cultural Communication, 7(1), 43-52.

[41] Mitchell, R., \& Myles, F. (2004). Second language learning theories ( $2^{\text {nd }}$ ed.). London: Arnold.

[42] Nelson, G. (1994). Considering culture: Guidelines for ESL/EFL textbook writers. In P. Byrd (Ed.), Material writer's guide (pp. 23-42). Belmont, CA: Wadsworth.

[43] Papademetre, L., \& Scarino, A. (2006). Teaching and learning for intercultural communication: A multi-perspective conceptual and applied journey for teachers of world culture languages $\left(2^{\text {nd }}\right.$ ed.). Adelaide: UniSA.

[44] Pennycook, A. (1994). The cultural politics of English as an international language. New York: Longman.

[45] Peterson, E., \& Coltrane, B. (2003). Culture in second language teaching. http://www.cal.org/resources/digest/peyton02.html. (accessed 20/09/2017).

[46] Risager, K. (2005). Languaculture as a key concept in language and culture teaching. In F. B. Preisler, S. Kjaerbeck, \& K. Risager (Eds.), The consequences of mobility (pp. 185-196). Roskilde: Roskilde University.

[47] Saluveer, E. (2004). Teaching culture in English classes. Master's thesis. University of Tartu, Department of English.

[48] Scarcella, R. C., \& Oxford, R. L. (1992). The tapestry of language learning: The individual in the communicative classroom. Boston, MA: Heinle \& Heinle.

[49] Seelye, N. (1976). Teaching culture: Strategies for foreign language educators. Lincolnwood: National Textbook Company.

[50] Singhal, M. (1998). Teaching culture in the foreign language classroom. http://www.thaitesol.org/bulletin/1101/110102.html. (accessed 09/05/2017).

[51] Sulaimani, A., \& Elyas, T. (2015). A critical review of the CELTA syllabus within the context of Saudi Arabia. International Journal of English Linguistics, 5(2), 100-105.

[52] Tomalin, B. (2008). Culture the fifth language skill. British Council. https://www.teachingenglish.org.uk/article/culture-fifthlanguage-skill. (accessed 12/07/2017).

[53] Valdes, J. M. (1986). Culture bound: Bridging the cultural gap in language teaching. Cambridge, UK: Cambridge University Press.

[54] Vernier, S. S., Barbuzza, S. D., Giusti, \& Moral, G. D. (2008). The five language skills in the EFL classroom. Nueva Revista de LenguasExtranjeras, 10, 263-291.

[55] Wallen, N. E., \& Fraenkel, J. R. (2001). Educational research: A guide to the process. New Jersey: Lawrence Erlbaum Associates Publishers.

[56] Yasemin, K., \& Reyhan, A. (2011). Exploring culture in locally published English textbooks for primary education in Turkey, CEPS Journal, 1(1), 153-167.

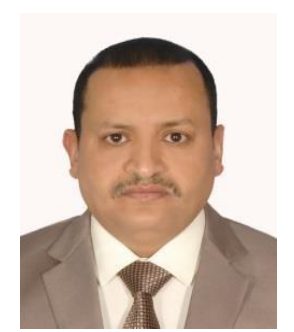

Bakr Bagash Mansour Al-Sofi received a PhD degree (2012) and an MA degree (2007) in "Language, Culture, \& Communication" from Moulay Ismail University in Morocco. He got a BA degree (2003) in English Studies from Faculty of Arts, Ibb University, Yemen. He was a teacher of English in high school, Yemen (2004-2005). He was an assistant professor of English at King Khalid University, Saudi Arabia (2013-2015). Currently, he is an assistant professor of English at University of Bisha, Saudi Arabia. He is a head and a member of many committees in the college. He participated in many conferences and workshops. He has published many articles in refereed international journals. He is also the author of the book: Intercultural Communication Competence among Yemeni English Learners: A Linguistic Intercultural Study (Scholars' Press, 2014). His research interests include Applied Linguistics, Sociolinguistics, Cultural Studies, and E-learning. His orcid ID is: orcid.org/0000-0001-6115-313X 